\title{
Implications of Globalized Human Resource Management Practices in Organizations in Pakistan - An Academic Perspective
}

\author{
Dr. Mustafa Hyder, PhD, Assistant Professor \\ Ms. Tehmina Faisal, MPA (HRM), Lecturer
}

Department of Public Administration, University of Karachi, Pakistan

Doi:10.19044/esj.2019.v15n10p278 URL:http://dx.doi.org/10.19044/esj.2019.v15n10p278

\begin{abstract}
Since the 1940's, businesses have moved beyond local markets and gradually developed into one sophisticated multiethnic and multiracial economies; a trend we today conceptualize as globalization. Through liberated flow of technology and human resources across local boundaries, international organizations are enabled to explore infinite opportunities within limited resources. Globalization, however, has immensely increased responsibilities of the HR practitioners specifically in terms of employee growth and wellbeing. Comprehensive data collection technique of structured open ended interviews from HR practitioners of multi-national and local business concerns was utilized, simultaneously relevant literature was also reviewed to further conceptualize and clarify the implications of implementing globalized HR practices to organizations performing in local scenario. This analytical paper explores HR practices in Pakistan and how efficacious organizations embrace globalization as a challenging yet profitable phenomenon.
\end{abstract}

Keywords: Globalization, HR and Pakistan, Human Modernization, Technological Innovations, Building Blocks of Global HRM

\section{Research Objectives:}

This analytical research is conducted to conccpetualize how globalization has effected HR practices in Pakistan. The research seeks to:

1. Comprehend the phenomenon of globalization with specific relevance to HR Practices in Pakistan

2. Identify the major building blocks that uphold HR functions and practices in organizations working globally.

3. Identify and discuss the challenges that HR practitioners are facing under an international working scenario, specifically emphasizing on multinational and local business concerns in Pakistan. 
4. Suggest ways through which organizations may improve HR functions and practice to increase efficiency and effectiveness.

\section{Research Methodology:}

The analytical research has been conducted through the utilization of the comprehensive structutred open ended interviewsof HR practitioners from 10 multi-national and 5 local profit oriented organizations from Pakistan, to discuss in detail how globalization has effected HR functions and their implementation in Pakistan; simultaneously detailed reviews of literature, relevant to the topic, have also been conducted to strengthen the concepts discussed in the paper.

\section{Globalization - The HRM Picture}

Globalization has been an evolutionary and dynamic process that has served as a significant milestone in setting new arenas for the advancement of both human and technological resources. Most concede that at the end of World War II the demographical and geographical dynamics of the world changed that lead nations to believe in the principles of diversity and interdependency for their economic, social, culture and ethical sustenance and development; thus the notions of integration and standardization were deliberated and established(A.W.Purdue, 2016). The global economic climate was also fueled by phenomenonal progression in the telecommunication sector that till date has the most significant role in stratifying and linking global consumption and production markets. Thus 'globalization' has linked financial, human, material, technological and other resources among nations on the notions of integration and standardization to further develop and establish competitive markets.

Globalization embarks a significant impact in improving quality of life in the developing countries, it advances and broadens technological knowledge and application, and recreates the concepts of 'political liberation" (Held, 1997) while significantly developing opportunities for resource sharing. It has been observed that countries that show sustained progression in the Human Development Index (HDI), a comparative measure of the social political and economic growth of various countries, have more diligently explored and embraced social political and economic opportunities of globalization(Passaris, 2006). There exists a strong association between the exploration and recognition of global opportunities and the state's provision of quality life for its citizens thus participants of globalization exhibit succession in such determining factors as gross domestic production per capita, life expectancy at birth, adult literacy, and the number of persons enrolled in educational institutions. This further emphasizes the notion that despite being an international phenomenon, globalization contributes 
considerably to domestic or national development of a country(WengJing, Ayenagbo, RongChen, \& Nguhi, 2012).

The roots of globalization lies under influence from other more developed countries. It has a strong impact on organizations all over the world. Our world of countries and states has now been transformed into a global village; multi-national corporations today place significant emphasis on their global presence and service provision; for example, the popular DHL advertisement shows "a suit stitched in Paris today is applauded in New York next day" or "a car made in Germany can be seen on the roads of Karachi next day". County Cricket, Olympics or FIFA are other examples, where the best players from various parts of the globe are evaluated and structured to play variety of sports that captures attention of the world while also contributing to branding and market expansion of several other relevant businesses such as sports goods industry, or food and beverages industry etc. Globalization has revolutionized the field of medicine(Lee \& Med, 2004) and health; treatments, technologies and procedures that were earlier confined to certain boundaries are now available to patients at large.

However, this very mechanism of globalization has lead to, probably, the most controversial debate of our times; whether globalization is a blessing or curse for local and multinational business concerns? Since globalization has increased fortitude of competition existing in the market and simultaneously, the risks for the new or small business concerns. It is, however, only possible to study the dynamics and complications of global business markets after a comprehensive understanding of nations' interdependence in sharing knowledge, skills and resources.

The escalating phenomenon of globalization has also significantly reformed the strategies, policies and practices of human resource management(Horwitz \& Mellahi, 2009). Multi-national concerns have a broader platform for recruitment and selection of skilled employees from various economies from around thw world, also different recruitment firms working in underdeveloped countries send skilled workers on relatively higher wages (as compared to their local market) to the international market. According to Hodgetts and Luthans (2003), a multinational corporation (MNC) is "a firm that has operations in more than one country, international sales, and a nationality mix of managers and owners."When dealing with multinational corporations and the field of international business management there are four primary areas that must be taken into consideration: country environment, culture, organizational strategy, and organizational behavior(R.M.Hodgetts \& Luthans, 2003).

Globalization is often taken as a driving force for growth and expansion, and has a prime role of supporting and motivating developing countries(Ikyanyon \& Ode, 2017). The main direction of change is seen as 
from 'traditional' employment security and seniority-based systems of employee resourcing and rewarding, towards 'newer' flexible and performance-based ones.

\section{The Building Blocks Of Global HRM}

Globalization is a process of standardization of everyday life experiences through the diffusion of commodities and ideas existing around the globe. Factors that have contributed to globalization include increasingly sophisticated infrastructure for communications and transportation services, mass relocations and movement of people, a level of economic activity that has expanded beyond national markets through industrial combinations and commercial groupings that cross national frontiers and international agreements reducing the cost of doing business in foreign countries. Globalization offers huge potential profits to companies and nations but has been complicated by widely differing expectations, standards of living, cultures and values, and legal systems as well as unexpected global cause and effective linkages.

People, Technology and Business Strategies are the main building blocks of multinational organizations and HRM is the pillar of this horizon(Itika, 2011). Globally operating or multinational organizations are required to take series of deliberate actions in order to gain competitive advantage and this is not possible without adequate resources and proper strategic planning. In terms of resources, human resources are jack's seed for the beanstalk, the most crucial and influential factor. HR must be capable to hire and tackle skilled and competitive work force from all over the globe.

- People - essential foundations of business; integrated with strategic, financial, material and technological capabilities to cater to global needs.

- Technology - HRIS and other state-of-the-art HR techniques, resource processes, knowledge and skills to implement contemporary HR practices.

- Business Strategies - a tactical amalgamation of skills in problem solving, management of change, leadership etc that later materializes to be implemented for the evolution and creation of a new culture.

Organizations are also witnessing an alteration in systems, management values and philosophies due to the global business dynamics. The need for incorporating multiple skills set has led Human resource management to become more strategic and preemptive in nature(Al-Raggad, 2014).The foundations of Human resource management affirm its concept as the procedure for bringing people and organizations together for the achievement of mutually exclusive objectives. Nevertheless, the conventional Human Resource roles and practices have evolved from employee hiring and 
development to employee care; that has significantly raised the benchmark for Human Resource Departments and its professionals. Contemporary organizations not only aim to increase productivity but also place increased emphasis on quality of work life, legal compliance, gaining competitive advantage and workforce adaptability (Bloom \& Reenen, 2011). Thushuman resource professionals are now expected to understand the internal and external business environment; plan and staff the organization for human resource needs; train and offer career management to employees; appraise and compensate employees; improve work environment; manage effective work relationships and organizational change(Burma, 2014). Personnel directors are now the new partners in good corporate governance, enhancing their traditional administrative and management roles to the more advance roles of policy formulators and strategists (Khan, 2014). Despite these developments the focus of human resource department has always been on the high demand for skilled human resources with relevant knowledge set to enhance an organization's effectiveness and efficiency. It is anticipated that development and advancement in global human resource practices would bring substantial changes to the organization's internal and external environment. The following factors would then be significant points of concern for any organization's human resource professionals.

\section{i. Attainment of Educated workforce:}

Due to technological advancements and spread of scholastic institutions among workforces, it has become increasingly significant that individuals being hired to serve an organization are adequately educated(Boxall, Purcell, \& Wright, 2008). Even such small tasks as attendance entry and leave application forms are now computerized and therefore an increased level of education is mandatory to manage the taskworker output balance. Consequently, the higher education of employees increases their level of need and satisfaction; better educated and organized workforce will demand greater discretion and autonomy at work place. Therefore it becomes a challenge for the human resource managers to evolve suitable policies and practices that motivate workers and improve employee experience within the organization.

\section{ii. Technological Developments:}

Advancements in technology have enabled organizations to take advantage of the information explosion. With computer networks unlimited amounts of data can be stored, retrieved and used in a variety of ways from simple record keeping to controlling complex equipment. This effect is so dramatic that on a broader level organizations are changing the way they do business. Use of internet to transact business has become pervasive for both 
large and small companies and e-commerce is rapidly becoming an organizational challenge for the new millennium(S.Sriram \& M.Arumugam, 2016). Following the 'dot com bust'(Epstein, 2004), in which many promising new internet companies failed rapidly, the Web is changing the way traditional brick and mortar companies do business. Organizations are connected through computer mediated relationships and they are giving rise to a new generation of 'virtual' workers who work from home, in hotels, in cars, or wherever their work takes them. Present era of communication has escalated the establishment of multinational corporations. However, HR practitioners should also keep in mind the impact of global recession on business strategy and employees.

\section{iii. Changing Composition of Work Force:}

The changing set of workforce values and demographic structures has caused serious concerns for HR practitioners in organizations. For example, women and minority groups are an important source of man power. However, recruitment and selection of individuals from such groups create further challenges of management of work force diversity and maintenance of ethical conduct codes. Therefore it becomes critical for HR practitioners to develop effective organizational strategy, structures and culture.

\section{iv. Structural Development:}

Change will have to be initiated and managed to progress organizational effectiveness. It is a common trend for organizations to restructure themselves to be most effective in terms of both quality and cost. Just as technology or organizational culture can restrict job design programs so can organizational structure(Gratton, 2013); particularly through the design of control structure in the organization. Such control structures specify employee responsibilities and accountability. Although this helps reduce the complexity for each job and responsibility of each worker, a stringent control structure often sets up personal boundaries that nurtures employee grievances. Role of HR practitioners, then, becomes critical in managing the behavior of people in the organization. A significant feature in development of organizational structures is management philosophy. Since top management is responsible for development of effective organizational structures, their ideologies and philosophies are quite evident from their design that may vary from closed structures to authoritative structures or even a more participative and democratic structure that promotes employee liberty and creative skills. However, none would disagree that organizations should move from legal and rule bound approaches to more open and humanitarian approach. 


\section{v. Workplace Ethics:}

Employee matters of grievances, harassment and discrimination have emphasized the top management's responsibility of establishing an ethical environment in the organization. HR practitioners worldwide consent to positive implications in establishing an ethical culture in organizations (Gravan \& McGuire, 2010)from the perspective of both normative and descriptive dimensions of ethical conduct(AstridEisenbeiss, 2012). As organizations become more project focused and believe in team working, a greater emphasis has to be given on individual and team ethics. Ethics programs may help generate legitimacy-enhancing organizational outcomes, a key indicator of corporate social performance and an important contributor to overall organizational success. Ethics programs can also contribute to legitimacy by signaling that the company conforms to societal expectations in its internal organizational protocols and processes.

The growing need of developing a conducive and supportive corporate culture can be observed from an extensive organizational commitment to ethics, sustainability and social responsibility that may significantly be pronounced in the mission and vision statements, rather adherence to such commitments are imperative in employee's appraisal and performance evaluations. Consequently, corporations have social responsibilities towards connecting communities encompassing extensive functions of corporate citizenship, social contract and enlightened self-interest. These features of a progressive and supportive corporate culture not only create desirable implications for the internal and external publics of an organization but also prove to be milestones in evolving Good Corporate Governance.

\section{vi. Competitive Appraisal and Reward Systems:}

Organizations are required to segment gains of higher periodicity with workers. More humanistic, objective and result oriented systems of performance, appraisal and performance linked compensation are being developed. Unlike the baby boomers and the Generation X, the Generation Y (Millennials) and Generation $\mathrm{Z}$ employees have exceeding expectations from the employers especially those employers that operate globally. Such personnel pay much head to performance metrics that form the basis of their performance evaluation, in both objective and subjective terms. Thus the performance metric, its development, the Key performance indicators, the evaluation rating scale and most significant the compensation plan that is linked to these aspects of human resource management, will always remain crucial matters of concern for employees of globalized businesses. Development of a rational, reasonable and justifiable reward system is probably the most significant challenge that HR practitioners are facing in this time and age. For multinational organizations this issue creates bigger 
implications since two employees performing equal responsibilities with equal output, in two different countries, would expect to be rewarded equally. Therefore only a well-strategized and realistic reward system would be able to justify and operate in a globally operating business mechanism.

\section{vii. Global Investment}

The modern business is one of global magnitudes. Estimated world population as of January 2017 is 7.6 billion people in over 192 independent countries. Globalization has changed world of business forever. In 2004, world GDP equaled \$51.48 trillion with world trade amounting to over $\$ 12.9$ trillion ("The World Fact book," 2004). In 2012, World GDP was about \$65 trillion. In the year 2017 global output was significantly larger at 80 trillion US dollars ${ }^{1}$ but where will that next $\$ 10$ trillion be added? It will be shared globally depending on the size of a country's economy and its organizational infrastructure, its growth rate and the appreciation of its real exchange rate and year 2025 might be a game changer in the global industry.

\section{Human Resource Management in Pakistan}

Human Resource Management has been transformed and acknowledged as a significant functional unit of organizations. This transformation was not only an initiative taken by the organizations but was also anticipated by the employees who were prognostic of the benefits of establishing efficient Human Resource structures and mechanisms.

In the early years of its inception, Human Resource Management in Pakistan was fallaciously considered as the administrative department responsible for minor tasks. However, as notions of 'employee care' and 'ownership' emerged and organizations embraced these concepts; there came a significant shift in the functions and responsibilities of Human Resource Management. Consequently, these modifications first became apparent in multinational organizations in Pakistan that were parceled HR practice models from parent concerns internationally.

These modified mechanisms inspired local business establishment in their success; consequently the national and local business concerns were also able to forecast that embracing Human Resource ideologies is the only equipment that would facilitate them in surviving their competition in the tedious task of talent hunt. It became apparent that recruitment and selection would remain neglected in administrative structures and therefore it would be almost impossible to magnetize a pool of recruits and retain them as efficient and satisfied employees. Additionally, administrative structures were weak in

1 Details avaiable at https://www.statista.com/statistics/268750/global-gross-domesticproduct-gdp/ 
normative and evaluative mechanisms that could diagnose, identify and address employee concerns in terms of knowledge acquisition, learning and skill development. The prognostic and analytical approaches required to appraise employees were also a serious source of concern for both organizations and respective employees.

Thus these multi-dimensional aspects of employee retention and development and many others led to the recognition of Human Resource Management as a core organizational function and Human Resource Executives as professionals. Initially HR practice models were adopted from multinationals that successfully achieved results in terms of enhanced worker efficiency and effectiveness (Ahmed, 2012). However, as knowledge of the field grew and academicians were produced in the field along with professionals, HR models were developed or at times integrated with global HR practice models to make these mechanisms more effective during implementation at home.

Today, Human Resource Management Departments in Pakistan are engaged in recruiting and assisting senior management in day to day operations. Employees are spending satisfied number of hours at work. Additionally, human needs of mentoring, guidance, support and true advice are also being attended by $\mathrm{HR}$ professionals that sprout loyalty and commitment from the workforce. Even in these days of pronounced HR practices in Pakistan, it is often deliberated that Human Resource professionals must now place further value to the dynamism of their roles from their classical functions of record keeping and their contemporary responsibilities as participants in organizational policy making; to the immense commitment of 'employee ownership'(Pfeffer, 2010).

Consequently, there are extensive opportunities waiting for further establishment and evolution of Human Resource practices in Pakistan (Khilji, 2003). Operationally, HR practices are recognized as a procedural routine in most of the organizations wherein at least basic functions of recruitment, selection, training and development, performance appraisal etc. are being mechanically and efficiently performed. However, from a global perspective we are still at the primary stage of Human Resource Management. It is imperative to establish structural linkages and channels of Human Resource Management to standardized levels of business decision making. The global business community expresses this role of HR department as a strategic business partner; wherein it establishes a bridge of closer cooperate association between the employer and employee.

One of the major reasons why human resource management remains a developing field of business in Pakistan is due to the almost non-existent legal mechanism in terms of compliance to HR practices in corporations. Thus till date the government is unable to devise and implement a legal framework or 
even guidelines that obligates corporations to establish functional HR procedures and structures. Additionally the legal framework for employee protection and welfare is also very weak. The labor law 2002 is the only comprehensive document that ensures protection of workers in the nonexecutive cadre; thus giving organizations broad margins to escape costs in managing HR functions.

Another root cause reason that has imperative implications on the pace of development in HR practices in Pakistan is the snail pace of academic research in this field. Educational Institutions are more focused on developing professionals for field operations and best practices rather than producing researcher and analysts in field applications with specific interest in the dynamics of various market practices in Pakistan. Since the law does not bind the organizations to establish HR structures, they are under no obligation to finance applied research projects for enriching the field with enhanced academic value.

Serious professional attitude and expertise are required for the development of effective HRM practices in the country. Human Resource Management is being introduced in many companies in Pakistan thus expanding its scope.

\section{Human Resource Management Challenges Faced By Global Business Concerns Operating In Pakistan}

On a global scale, despite national and regional differences, there was remarkable unanimity. This is because organizations have achieved relatively low levels effectiveness in implementing Human Resource Management (HRM) practices especially in emerging economies like Pakistan and other developing countries that are exposed to the challenges and opportunities of globalization(Huselid, Jackson, \& Randall, 1997). The most important challenges as presented by the global groups and multinationals in Pakistan are:

\section{i. Change Management}

Change the only certainty in an organization should be significantly recognized as a crucial progress stimulator for an organization. The global business environment, along with several other challenges, establishes change as imminent. From evolution to revolution and transformation, organizational change, its recognition and management is a source of serious concern for local, national and multinational establishments alike. Incorporation of change management in planning, operations, procedures and culture of the business ensures absorption of financial and non-financial shocks and increases corporate stability. 
In addressing various issues related to planning, introducing, training, implementation and collection of feedback in managing consistent change, Human Resources contributes significantly(Cumming \& Worley, 2009). As an HR professional, executives are expected to facilitate change and ensure that the organization develops a culture of adherence and adaptability to changing external and internal business environments.

In Pakistan, it is believed that the best technique to induce change effectively is training and development. Large corporations dedicate a substantial amount of budgets and efforts to ensure that change is effectively comprehended and implemented. Effective Change management is a very daring challenge for personnel management staff as this area of expertise is generally not focused in training and development of HR professionals. This may also be the reason why it is cited as the prime issue as HR continues to endeavor to aid businesses move forward and expand. Trainings should be reformed to cater to challenges of change management by developing added competencies.

\section{ii. Leadership Development}

History affirms that businesses often establish and progress through its Leadership. The present day corporation holds serious concerns regarding development of successive leaders that are expected to pragmatically transform framework, processes, tools and ideologies in accordance to the strategic philosophies of the organization and the legislative, structural and social modifiers that exist in the external organizational environment.

HR experts continue to explore the best way to develop and nurture leaders for future succession planning(LynneLeskiw \& Singh, 2007). Globally leadership development has been identified as a critical strategic initiative for ensuring that the right employees are retained, philosophy of the organization and work culture supports performance to gain market position, and managers are fortified to take on leadership roles of the future so that an organization is sustainable in long term. This is equally important as more and more acquisitions and mergers are taking place in the country.

\section{iii. The Measurement of HR Effectiveness}

The measurement of efficiency of HR demands consultative approach where continuous dialogues(Ahmeti, 2014), open communication, participative decision making are very important. HR practitioners are expected to realize this role to procure a participative and democratic culture in the organization.

HR effectiveness rose as a significant area of concern as more and more multinational companies are being established at one end; while several local businesses are expanding to reach global market on the other hand; thus 
significantly increasing workforce diversity in organizations. Managing these people with different religious, cultural and moral background is a challenging task for HR practitioners. Despite being financially and intellectually beneficial managing an asymmetrical work force is a critical issue that has direct implications on employee commitment, motivation and turnover along with organization's public relations. Thus it comes down to the HR manager(s) to play safe and device effective retention strategies based on equal employment opportunity and affirmative action plan(s).

\section{iv. Stress and Conflict}

Long working hours, target pressures, high competition, workplace aggression and the potential impact of a global disease pandemic etc. adds stress and conflicts in an organization. Stress and conflict have been widely recognized to damage employee performance graphs. Researches show that they are severe repercussions of a stressed mind on the cumulative performance of an employee, similarly workplace conflicts also have severe implications on overall growth and production of an organization. A common cause of such work stress and conflict in Pakistan, like other developing countries, is the notion of inequalities.

It then becomes imperative for the HR Manager(s) to develop and implement a work culture based on equality, justice, social norms and ethical values. These traditional philosophies address the core of human satisfaction, directly reducing the implications of high level stress and unresolved conflicts. Additionally, such environments offer flexibility to maintain an effective work-life balance that ensures employee satisfaction both in personal and professional dimensions of life.

\section{Conclusion:}

Globalization has addressed many aspects of business however; it is not an instantaneous solution to all of an organization's hitches. Especially in the field of human resource management that is an excessively complicated domain. Advocates of globalized economies are often faced by conflicted opinions by the cynics of globalization that argue that it is causing the world to adapt to standards developed by more dominant western countries, there is a cultural opportunity cost associated with globalization. Thus for multinational organizations maintaining the balance of cultural preservance and competitive progression is imperative to its growth and success.

This paper set out as an input to the implications of globalization in a developing country like Pakistan. It presents a framework for Human Resource Management practices in perspective of the global challenges faced by national and multi-national organizations existing in country. The real challenge for organizations in this era of globalization is to pay particular 
emphasis to strengthening their human resources by upgrading relevant competencies. It is true that there is sometimes loss of culture associated with globalization. However, let's not forget that not all culture is good. Globalization encourages independence and choices for all citizens and increases opportunities for both workers as well as organizations.

\section{References:}

1. A.W.Purdue. (2016, April 18). The Transformative Impact of World War II. Retrieved from ieg-ego.eu: Purdue, A.W.: The Transformative Impact of World War II, in: European History Online (EGO), published by the Leibniz http://www.ieg-ego.eu/purduea-2016-en

2. Ahmed, M. S. (2012). Impact of Organizational Culture on Performance Management Practices in Pakistan. Business Intelligence Journal, 50-55.

3. Ahmeti, D. F. (2014). HRM: Developing Organizational Communication Culture in Transitional Economies. European Scientific Journal, 301-312.

4. Al-Raggad, D. M. (2014). Strategic Human Resource Management and Firm Performance in Jordon Listed Firms. European Scientific Research, 402-421.

5. AstridEisenbeiss, S. (2012). Re-thinking ethical leadership: An interdisciplinary integrative approach. The Leadership Quarterly , 791- 808.

6. Bloom, N., \& Reenen, J. V. (2011). Human Resource Management and Productivity. In D. Card, \& O. Ashenfelter, Handbook of Labour Economics. Houghton Street, London: Centre for Economic Performance, London School of Economics.

7. Boxall, P., Purcell, J., \& Wright, P. M. (2008). Human Resource Management: Scope, Analysis, and Significance. In P. Boxall, J. Purcell, \& P. M. Wright, The Oxford Handbook of Human Resource Management (pp. 1-17). Oxford Handbooks online: Orford University Press.

8. Burma, Z. A. (2014). Human Resource Management and Its Importance for Today's Organizations. International Journal of Education and Social Science, 85-94.

9. Cumming, T. G., \& Worley, C. G. (2009). Organization Development and Change. Natrop Boulevard, Mason, USA: South Western CENAGE Learning.

10. Epstein, M. J. (2004). Implementing E-Commerce Strategies - A guide to Corporate Success After the Dot Com Bust. Connecticut, London: Praegar Publishers. 
11. Gratton, T. J. (2013). The Third wave of virtual work. Harvard Business Review, 66-73.

12. Gravan, T. N., \& McGuire, D. (2010). Human Resource Development and Society: Human Resource Development's Role in Embedding Corporate Social Responsibility, Sustainability, and Ethics in Organizations. Advances in Developing Human Resources , 487-507.

13. Held, D. (1997). Democracy and Globalization. MPIfG Lecture Series Economic Globalization and National Democracy (pp. 3-14). UK: HeinOnline.

14. Horwitz, F. M., \& Mellahi, K. (2009). Human Resource Management in Emerging Markets. In D. G. Collings, \& G. Wood, Human Resource Management: A Critical Approach (pp. 263-277). USA, Canada: Routledge, Taylor and Francis.

15. Huselid, M., Jackson, S., \& Randall, R. (1997). Technical and Strategic Human Resource Management Rffectiveness as Determinants of Firm Performance. Academy of Management Journal, 171-188.

16. Ikyanyon, D. N., \& Ode, E. (2017). Fostering Knowledge Transfer Through High Performance HRM Practice; The Mediating Role of Active Commitment. European Scientific Journal, 374-389.

17. Itika, J. S. (2011). Fundamentals of Human Resource Management: Emerging Experiences from South Africa. Leiden: African Studies Centre.

18. Khan, D. M. (2014). HR as a Strategic Partner: A Critical Review. International Journal of Human Resource Studies.

19. Khilji, S. E. (2003). Human Resource Mangement in Pakistan. In P. S. Budwar, \& Y. A. Debra, Human Resource Management in Developing Countries (pp. 102-120). New York: Routledge.

20. Lee, K., \& Med, J. (2004). Globalisation: what is it and how does it affect health? The Medical Journal of Australia, 158-167.

21. LynneLeskiw, S., \& Singh, P. (2007). Leadership Development: Learning from the Best Practices. Leadership and Organizational Development Journal, 444-464.

22. Passaris, C. E. (2006). The Business of Globalization and the Globalization of Business. Journal of International Comparative Management.

23. Pfeffer, J. (2010). Business and Spirit: Management Practices that Sustain Value. In R. A. Giacalone, \& C. L. Jurkiewicz, Handbook of Workplace spirituality and Organizational Performance (pp. 27-42). New York: Routledge .

24. R.M.Hodgetts, \& Luthans, F. (2003). International Management: Culture, Strategy and Behaviour. New York: McGraw Hills. 
25. S.Sriram, \& M.Arumugam. (2016). E Commerce and Human Resource Management. Innovative Management Practices (pp. 327329). Virudhunagar: Area Studies Centre.

26. WengJing, W., Ayenagbo, K., RongChen, W., \& Nguhi, S. (2012). The impact of globalization on African countries economic development . African Journal of Business Management , 11057-11076. 